\title{
EDUCAÇÃO PARAA MORTE E O LUTO, UMA ESTRATÉGIA COMPLEMENTAR À FORMAÇÃO ACADÊMICA NA GRADUAÇÃO DE MEDICINA: RELATO DE EXPERIÊNCIA
}

\begin{abstract}
Larissa Sena de Lucena ${ }^{1}$
${ }^{1}$ Discente de Medicina do $8^{\circ}$ período, Universidade Federal do Amapá (UNIFAP), Macapá, Amapá.
\end{abstract}

DOI: 10.47094/IICNNESP.2021/94

\section{RESUMO}

A morte e o luto fazem parte da prática médica, mas são temas escassos no âmbito estudantil, o que dificulta a compreensão e a atuação dos graduandos em medicina para lidarem com esses elementos na rotina. Desse modo, o estudo objetivou relatar uma experiência online que buscou discutir nuances relacionadas à morte e ao processo de luto. Com isso, houve o uso de metodologias ativas e a interação entre os participantes do evento possibilitando a elaboração de um espaço de ressignificação da morte, além do fomento de momentos reflexivos sobre o papel do profissional e das emoções surgidas no contexto da perda. Concluindo-se que é necessário ampliar as discussões sobre a temática da morte e do luto na graduação, visando capacitar integralmente os estudantes para uma abordagem humana e ética, bem como incluir as atividades complementares para uma formação médica condizente com as diretrizes curriculares nacionais.

PALAVRAS-CHAVE: Educação Médica. Grupo. Aprendizagem ativa.

ÁREA TEMÁTICA: Educação em Saúde.

\section{INTRODUÇÃO}

É cediço que a morte, inserta no processo natural da vida, caracteriza-se pela interrupção das funções vitais (SANTANA et al., 2011), como efeito da inexistência de atividades cerebrais. Assim, imbricado a tal contexto, o luto consiste na experiência humana associada à perdas, marcado por fatores como: emoções, cognições, sensações físicas e alterações comportamentais (MARTIN; WORDEN, 2019; WALLACE et al., 2020). Com efeito, pode-se afirmar que tanto o evento final da vida humana, quanto o fenômeno luto, despertam sentimentos e reações diversas em cada indivíduo (BANDEIRA et al., 2014; SARAIVA et al., 2020), variando conforme suas vivências e experiências passadas. Noutra perspectiva, na seara médica, salienta-se que subsiste uma perspectiva que retrata a morte como uma falha dos cuidados médicos (HO et al., 2020), como reflexo da lacunosa formação no ensino dessa competência nas Universidades (BATISTA; FREIRE, 2019; SIKSTROM, et al. 2019; AZEREDO; ROCHA; CARVALHO, 2011) o que compromete uma experiência com a morte de forma mais harmônica, conquanto as Diretrizes Curriculares Nacionais dos cursos na área de saúde reafirmam a necessidade das Instituições de Ensino Superior em formar profissionais para lidarem com as necessidades dos pacientes e de seus familiares, sobretudo quanto ao processo de 
enlutamento (PINELLI et al., 2016). O presente trabalho objetivou relatar a experiência vivenciada na oficina "Debate sobre as Perdas: Enfrentando o Luto e a morte" e conhecer a percepção dos participantes sobre essa experiência promovida por discentes do curso de graduação em Medicina em uma instituição de ensino superior do norte do Brasil.

\section{RELATO DE EXPERIÊNCIA}

A experiência foi vivenciada no primeiro semestre de 2021 em uma plataforma online para preservar as orientações de distanciamento social durante a Pandemia da COVID-19 e continuar promovendo a discussão da morte e da assistência nas perdas, uma vez que a formação tem que ser continuada. A oficina foi iniciada através de questionamentos norteadores elaborados pelos discentes sobre o processo de morte e enlutamento e divididos em quatro blocos temáticos sobre: a participação no grupo de apoio, estratégias de enfrentamento, sentimentos inerentes ao luto e formação acadêmica, totalizando nove perguntas. $\mathrm{O}$ evento ocorreu com a participação de quatro integrantes de um grupo de apoio, a docente psicóloga e quatro acadêmicos de medicina, sendo dois do $2^{\circ}$ ano e dois do $4^{\circ}$ ano, e visou aperfeiçoar às habilidades do público frente às perdas.

\section{RESULTADOS E DISCUSSÕES}

As atividades de caráter complementar atuam no aprimoramento(CRUZ et al., 2019) e fornecem ferramentas para o discente lidar com os dilemas encontrados na prática clínica, desempenhando papel relevante na formação acadêmica. Um desses dilemas é o estudo sobre a morte e dos sentimentos e sofrimentos referentes às perdas, é notório que uma parcela considerável de graduandos em medicina se sinta despreparada para lidar com essa situação na formação médica (SARAIVA et al., 2020), dificultando a compreensão da terminalidade da vida.

Dessa forma, a vivência oportunizou a aplicação de diferenciadas metodologias ativas de ensino para trabalhar as estratégias de enfrentamento ao luto tais como a construção de redação reflexiva e debates, a fim de ampliar o conhecimento nas etapas atreladas a perda. Importa ressalvar que, essa concepção educacional incentiva o autogerenciamento do processo de formação, além de viabilizar a aquisição de conteúdo de forma autônoma e participativa (TAKENAMI et al., 2018).

Essa experiência educacional possibilitou a interação das palestrantes e dos ouvintes de diferentes regiões do país, enriquecendo desta forma o debate e a troca de experiências. Ademais, buscou propor mecanismos para os discentes promoverem o suporte humanizado aos pacientes, permitiu elaborar um espaço de ressignificação da morte, bem como reflexões sobre o papel adequado do profissional e o gerenciamento das emoções despertadas no processo da perda. Tais instrumentos de educação para a morte (HAYASIDA et al., 2014) contribuem para o preparo durante a formação do ser médico e são essenciais para estabelecer um vínculo médico-paciente mais humanizado e uma comunicação mais adequada com os pacientes e familiares (SARAIVA et al., 2020). 


\section{CONSIDERAÇÕES FINAIS}

A oficina buscou capacitar o público quanto a necessidade de adquirir conhecimentos referentes à assistência no processo de luto e quais atitudes são essenciais na formação médica, bem como estimular medidas para estreitar a relação médico-paciente através da construção coletiva do conhecimento e do aperfeiçoamento das relações humanas por meio de gestos e ações humanizadas. O estudo da morte deve ser implementado desde o início da graduação médica e mantido ao longo da graduação, a fim de proporcionar maior integração entre os princípios e aplicação na rotina clínica uma vez que são fundamentais para um bom exercício profissional e excelência no cuidado com o paciente e os familiares num contexto de perda, bem como considerar práticas complementares para uma formação médica pautada nas diretrizes curriculares.

\section{PRINCIPAIS REFERÊNCIAS}

SANTANA, Júlio César Batista. et al. Preparando o corpo: respeito e ética no momento do fim da vida. Enfermagem Brasil, Minas Gerais, v. 10, n. 1., p. 25-31, jan./fev. 2011. Disponível em: < https:// portalatlanticaeditora.com.br/index.php/enfermagembrasil/article/download/3837/5838/23021>. Acesso em: 30 mai. 2021.

WALLACE, Cara. et al. Grief During the COVID-19 Pandemic: Considerations for Palliative Care Providers. J Pain Symptom Manage. v. 60(1): e70-e76. 2020. Acesso em: 30 mai. 2021. Disponível em: < https://pubmed.ncbi.nlm.nih.gov/32298748/>.

MARTIN, Terry; WORDEN, William. Grief counseling and grief therapy: a handbook for the mental health practitioner. OMEGA - Journal of Death and Dying. Nova Iorque, v. 80, issue 2, p. 331-334. 2019. Acesso em: 30 mai. 2021. Disponível em: <https://journals.sagepub.com/doi/ abs/10.1177/0030222819869396>.

BANDEIRA, Danieli. et al. Death and dying in the formation process of nurses from the perspective of nursing professors. Texto \& Contexto - Enfermagem [online]. 2014, v. 23, n. 02, pp. 400-407. Acesso em: 30 mai. 2021. Disponível em: <https://doi.org/10.1590/0104-07072014000660013>.

SARAIVA, Katleem Sousa. et al. Percepção do estudante de medicina sobre o preparo para lidar com a morte no cotidiano da graduação. Braz. J. of Develop.,Curitiba, v. 6, n. 1, p.5117-5130. jan. 2020. Acesso em: 30 mai. 2021. Disponível em: <https://www.brazilianjournals.com/index.php/ BRJD/article/view/6540/5771>.

HO, Chong Yao. et al. The impact of death and dying on the personhood of medical students: a systematic scoping review. BMC Med Educ. 20, 516. 2020. Acesso em: 30 mai. 2021. Disponível em: < https://bmcmededuc.biomedcentral.com/articles/10.1186/s12909-020-02411-y\#citeas>.

BATISTA, George Felipe de Moura; FREIRE, Gustavo da Cunha Lima. Análise do ensino da morte e do morrer na graduação médica brasileira. Rev Bras Bioética. 15(e3):1-13. 2019. Acesso em 16 mai. 2021. Disponível em: <https://periodicos.unb.br/index.php/rbb/article/ 
SIKSTROM, Laura. et al. Being there: A scoping review of grief support training in medical education. 2019. PLoS ONE. 14(11): e0224325. Acesso em: 15 mai. 2021. Disponível em: <https:// journals.plos.org/plosone/article?id=10.1371/journal.pone.0224325>.

AZEREDO, Nára Selaimen Gaertner; ROCHA, Cristianne Famer; CARVALHO, Paulo Roberto Antonacci. $O$ enfrentamento da morte e do morrer na formação de acadêmicos de Medicina. Rev. bras. educ. med., Rio de Janeiro, v. 35, n. 1, p. 37-43, mar. 2011. Acesso em: 17 mai. 2021. https://doi.org/10.1590/S0100-55022011000100006. Disponível em: <https://www.scielo.br/pdf/ rbem/v35n1/a06v35n1.pdf $>$.

10- PINELI, Paula Pereira. et al. Cuidado Paliativo e Diretrizes Curriculares: Inclusão Necessária. Rev. bras. educ. med., Rio de Janeiro, v. 40, n. 4, p. 540-546, dez. 2016. Acesso em 18 mai. 2021. http://dx.doi.org/10.1590/1981-52712015v40n4e01182015. Disponível em: < https:/www.scielo.br/ scielo.php?script $=$ Sci_arttext\&pid $=$ S0100-55022016000400540 > .

CRUZ, Marcelo Leandro Santana. et al. Perfil das Atividades Complementares dos Graduandos em Medicina pela Universidade Estadual de Feira de Santana, 2009-2017. Revista Brasileira de Educação Médica [Online]. v. 43. n.1.p. 265-275. 2019. Supl 1. Acesso em: 12 mai. 2021. Disponível em: $<$ https://www.scielo.br/scielo.php?pid=S0100-55022019000500265\&script=sci_arttext $>$. 